\title{
Intravenous fluid replacement minimised dehydration during sodium picosulphate bowel preparation for colonic surgery
}

Sanders G, Mercer SJ, Saeb-Parsey K, et al. Randomized clinical trial of intravenous fluid replacement during bowel preparation for surgery. Br J Surg 2001 Oct;88:1363-5.

\section{QUESTION: In patients receiving sodium picosulphate (Picolax $\left.{ }^{\circledR}\right)$ bowel preparation before colonic surgery, does intravenous fluid replacement minimise dehydration?}

\section{Design}

Randomised (unclear allocation concealment), unblinded, controlled trial with follow up to 1 hour before surgery or immediately before premedication.

\section{Setting}

Colorectal Unit, Derriford Hospital, Plymouth, UK.

\section{Patients}

41 patients (median age $69 \mathrm{y}, 63 \%$ men) who were receiving bowel preparation for colonic surgery. Follow up was $100 \%$.

\section{Intervention}

19 patients were allocated to receive a calculated volume (mean $2 \mathrm{l}$ ) of intravenous normal saline (treatment group), and 22 were allocated to receive no intravenous fluid (control group) during bowel preparation. Intravenous fluid administration (hourly infusion rate $4 \mathrm{ml} / \mathrm{kg}$ for the first $10 \mathrm{~kg}, 2 \mathrm{ml} / \mathrm{kg}$ for the second $10 \mathrm{~kg}$, and $1 \mathrm{ml} / \mathrm{kg}$ for each subsequent $\mathrm{kg}$ ) began at the same time as Picolax ${ }^{\circledR}$ (Ferring Pharmaceuticals, Langley, UK) administration. Each group received 2 sachets of Picolax $^{\circledR} 6$ hours apart, starting 18 hours before surgery, and were encouraged to drink unlimited clear fluids until 6 hours before surgery.

\section{Main outcome measures}

Physiological (weight, pulse, and supine and erect blood pressure), haematological (haemoglobin and haematocrit), and biochemical (sodium, potassium, urea, creatinine, and urine osmolality) variables measured immediately before starting bowel preparation and repeated 1 hour before surgery or immediately before premedication.

\section{Main results}

The treatment group had a lower mean weight loss, postural change in systolic blood pressure, and serum creatinine concentration than the control group (table).

\section{Conclusion}

Simultaneous intravenous fluid administration during bowel preparation before colonic surgery minimised the dehydrating effect of Picolax ${ }^{\circledR}$.

\section{COMMENTARY} before fasting for surgery. of Sanders et al to all low volume preparations. colon resection. South MedJ 1997;90:526-30. colorectal surgery. Dis Colon Rectum 1996;39:369-73. 1996;51:566-9.
Source of funding: not stated.

For correspondence: Mr A W Lambert, Colorectal Unit, Department of Surgery, Derriford Hospital, Plymouth, UK.

Anthony.lambert@ phnt.swest.nhs.uk

Preparing the bowel for surgery can increase risk of fluid and electrolyte imbalance, which, if uncorrected, can lead to hypotension during anaesthesia. Successful strategies to ensure that patients having colorectal surgery are adequately hydrated are therefore imperative. Encouraging patients to increase their oral fluid intake during bowel preparation is currently the most common strategy used by nurses to minimise dehydration

This well done trial by Sanders et al, however, supports the administration of intravenous fluids during oral lavage preparation with Picolax ${ }^{\mathbb{1}}$. Study limitations include a short duration of follow up, and failure to consider cost implications. Improvement in hydration by the administration of intravenous fluids was clearly shown, but postoperative benefits could not be determined because follow up occurred only until 1 hour before surgery or immediately before premedication.

Previous studies comparing outpatient (no intravenous fluid support) with inpatient bowel preparation have found no difference in postoperative complication rates. ${ }^{12}$ These studies also achieved considerable cost savings by reducing the length of stay before surgery. It should be noted that the laxative in these studies was polythylene glycol solution involving up to $4 \mathrm{l}$ of fluid. There is a trend towards the use of low volume preparations, such as Picolax ${ }^{\circledR}$, and clinicians should be cautious in applying the findings

Most comparisons of colonic cleansing for investigative procedures have found little difference in effectiveness between cleansing regimens, and instead focused on patient preference and side effects. ${ }^{3}$ Low volume preparations such as Picolax ${ }^{\circledast}$ and Fleet (phospho-soda buffered saline) are often preferred by patients. But a less aggressive outpatient regimen (ie, larger volume polyethylene glycol) may be desirable for patients at risk of fluid and electrolyte imbalance. The findings of Sanders $e t$ al suggest a safe and effective preoperative strategy for these patients if inpatient care is required.

Jane Brosnahan, RCpN, BN Clinical Nurse Consultant Auckland Hospital Auckland, New Zealand

1 Le TH, Timmcke AE, Garthright JB Jr, et al. Outpatient bowel preparation for elective

2 Lee EC, Roberts PL, Taranto R, et al. Inpatient vs outpatient bowel preparation for elective

3 Lai AK, Kwok PC, Man SW, et al. A blinded clinical trial comparing conventional cleansing enema, Pico-salax and Golytely for barium enema bowel preparation. Clin Radiol

Intravenous normal saline replacement (treatment) v no intravenous fluid replacement (control) during Picolax $x^{\circledR}$ bowel preparation for colonic surgery*

\begin{tabular}{llccll}
$\begin{array}{l}\text { Outcomes at } 1 \text { hour before surgery or immediately before } \\
\text { premedication }\end{array}$ & Treatment & Control & \multicolumn{2}{c}{ Difference (95\% Cl) } & p Value \\
Change in body weight from baseline $(\mathrm{kg})$ & -0.5 & -1.6 & $1.1(0.4$ to 1.8$)$ & 0.01 \\
\hline Postural change in systolic blood pressure from baseline $(\mathrm{mm} \mathrm{Hg})$ & -2.8 & 8.8 & $11.6(\mathrm{~N} / \mathrm{R})$ & 0.015 \\
\hline Change in creatinine concentration from baseline $(\mu \mathrm{mol} / \mathrm{l})$ & -3.8 & 1.8 & $5.6(1.5$ to 9.7$)$ & 0.008 \\
\hline
\end{tabular}

*Abbreviations defined in glossary; $\mathrm{Cl}$ calculated from data in article. N/R=not reported. 